\title{
Impact of Mobile Telephone on Technical Efficiency of Wheat Growing Farmers in Ethiopia
}

\author{
Kaleb Kelemu
}

Ethiopian Institute of Agricultural Research

\begin{abstract}
This paper investigates the impact of mobile telephone on technical efficiency of wheat producing farmers in Ethiopia using data collected by Ethiopian Institute of Agricultural Research and International Maize and Wheat Improvement Center (CIMMYT). The study indicated significant impact of mobile telephone on technical efficiency implying the potential role of mobile telecommunication service in improving overall wheat productivity through improving technical efficiency of farmers.
\end{abstract}

Keywords: Technical efficiency, mobile telephone and wheat producing farmers.

\section{INTRODUCTION}

Information and communication technologies (ICTs) have always mattered in agriculture. Ever since people have grown crops, raised livestock, and caught fish, they have sought information from one another (World bank, 2011). ICTs have a demonstrably positive effect on income growth in developing and developed countries (Röller and Waver man, 2001). In rural areas, ICTs can raise incomes by increasing agricultural productivity and efficiency (Lio and Liu 2006).

ICT is an umbrella term that includes anything ranging from radio to satellite imagery to mobile phones or electronic money transfers. The increases in their affordability and accessibility have resulted in their wider use even within rural communities that depend on agriculture as a means of livelihood. Mobile telephone is one of the most rapidly expanding ICT being used in agriculture, industry, commercial and other sectors of an economy. Five main trends have been the key drivers of the use of mobile telephone in agriculture, particularly for poor producers: (1) low-cost and pervasive connectivity, (2) adaptable and more affordable tools, (3) advances in data storage and exchange, (4) innovative business models and partnerships, and (5) the democratization of information, including the open access movement and social media. These drivers are expected to continue shaping the prospects for using ICT effectively in developing country agriculture (Tele Geography, 2011).

The importance of mobile telephone could be explained as it can easily overcome the geographic hurdles that have prevented remote areas from receiving modern communication in the past. Mobile can help farmers improve agricultural productivity and efficiency by giving them access to information on new agricultural techniques and financial services and new markets, in turn helping them to get information on input sources, receive advices from relatives and friends and experts, secure better prices for crops and get a better return on investments (Accenture and Vodafone, 2011).

Among the many support services rendered to agriculture sector in general and farm households in particular, telecommunication service through expansion of mobile telephone is the most crucial one. Recognizing the immense potential to transforming agriculture, Ethiopia is investing an unusually large amount, around $10 \%$ of its GDP, into information and communication technology (ICT). Specifically, the government has invested around USD 15 billion over the past ten years to expand mobile telephone in the country (Dominique, 2010).

There are very few studies indicating the potentials of mobile telephone in improving the economy. Minten et al. (2012) indicated in Ethiopia, access to mobile phones has improved traders and brokers' business communication for negotiating prices and settling payments. The study conducted by Getaw and Godfrey (2015) on the impact of mobile telephone on marketing decision and an assessment conducted by Alene et al (2008); Fafchamps \& Minten (2012) and Muto \& Yamano (2009) on the link between ICT and farmer's market participation have found that access to mobile phone did not 
significantly improve farmers' market participation and spatial arbitrage. However, there is no previous study in Ethiopia assessing the impact of mobile telephone on technical efficiency. This study was, therefore, conducted to evaluate the impact of mobile telephone on technical efficiency of wheat producing famers in Ethiopia.

The paper is organized as follows. The second section presents conceptual framework explaining the role of mobile telephone in improving efficiency. The third chapter discuss the analytical approach adopted in the analysis and empirical procedure used in evaluating impact of mobile telephone. The fourth section present the sampling and data collection techniques employed. The fifth and sixth section presents the results and discussions and conclusion and recommendation, respectively.

\section{CONCEPTUAL FRAMEWORK: ROLE OF MOBILE TELEPHONE IN IMPROVING Agricultural Production and EFficiency}

Farmers access to information input and output market, price and technical information is key for improving efficiency and productivity. Transaction costs for searching information are key factor that determine farmer's access to information. Transaction costs depend on the nature of transaction (Williamson, 1979) and the extent of information asymmetry and searching (Fafchamps, 2004; Stiglitz, 1986). Transaction costs depend on asset specificity, frequency of transaction, and uncertainty of transaction, which mainly stems from information uncertainty (Williamson, 1985). Information searching is costly in Africa (Fafchamps, 2004) which may impede farmer from accessing various agricultural information from different sources. In general, information searching cost is an important component to improve farm households' production and marketing decisions which ultimately enhance their production efficiency.

Mobile phone is one of the ICT innovations that provide enormous potential for reducing information searching costs not only in agriculture but also in other sectors of the economy (Aker \& Mbiti, 2010). The importance of mobile telephone could be explained as it can easily overcome the geographic hurdles that have prevented remote areas from receiving modern communication in the past (Aker, 2008). Mobile telephone can help farmers improve agricultural productivity and efficiency by giving them access to information on new agricultural techniques and financial services and new markets, in turn helping them to get information on input sources, receive advices from relatives and friends and experts, secure better prices for crops and get a better return on investments (Accenture and Vodafone, 2011).

\section{Analytical ApProach ANd Estimation Procedures}

Many literature on impact evaluation in observational studies repeatedly pointed out the problem of causal inference in estimating treatment effects. It is well recognized that the estimate of a causal effect obtained by comparing a treatment group with a non-experimental comparison group could be biased because of problems which emanate from self-selection or some systematic preferential program placement. Therefore, the main challenge of a credible impact evaluation is the construction of the counterfactual outcome, that is, what would have happened to participants in absence of treatment (Heinrich et al., 2010). Since this counterfactual outcome is never observed, it has to be estimated using statistical and econometric methods.

The use of micro econometric techniques to estimate the effects of development policies has become a common approach in evaluating project impacts in different fields. Among these techniques, Propensity Score Matching (PSM) is increasingly applied in the policy evaluation community (Heinrich et al., 2010).For example, Heckman, Ichimura and Todd (1998), Lechner (1999), Dehejia and Wahba (2002), and Smith \& Todd (2005) used PSM techniques to estimate the impact of labor market and training programs on income; Jalan and Ravallion (2003) evaluate antipoverty workfare programs; and Persson, Tabellini and Trebbi (2003) analyzed the impact of electoral reform on corruption. This study also employ PSM to estimate the impact of mobile telephone on technical efficiency of wheat producing farmers in Ethiopia.

PSM uses information from a pool of units that do not participate in the intervention to identify what would have happened to participating units in the absence of the intervention. By comparing how outcomes differ for participants relative to observationally similar nonparticipants, it is possible to estimate the effects of the intervention. 
The general idea of PSM is straightforward. It involves pairing treatment and comparison units that are similar in terms of their observable characteristics. When the relevant differences between any two units are captured in the observable (pretreatment) covariates, which occurs when outcomes are independent of assignment to treatment conditional on pretreatment covariates, matching methods can yield an unbiased estimate of the treatment impact (Bassi, 1984; Cochran and Rubin, 1973; and, Rosenbaum, 1995).

The motivation for focusing on propensity score matching methods is that, in many applications of interest, the dimensionality of the observable characteristics is high. With a small number of characteristics, matching is straightforward. However, when there are many variables, it is difficult to determine along which dimensions to match units or which weighting scheme to adopt. Propensity score-matching methods are especially useful under such circumstances because they provide a natural weighting scheme that yields unbiased estimates of the treatment impact (Dehejia and Wahba, 2002).

To substitute for the absence of experimental control units, we assume that data can be obtained for a set of potential comparison units, which are not necessarily drawn from the same population as the treated units but for whom we observe the same set of pretreatment covariates, $X_{\mathrm{i}}$. If for each unit we observe a vector of covariates $X_{i}$ and $y_{i 0} \perp T_{i} \mid X_{i}, \forall_{i}$, then the population treatment effect for the treated, $\left.\tau\right|_{T=1}$, is identified, it is equal to the treatment effect conditional on covariates and on assignment to treatment $\left.\tau\right|_{T=1, X}$, averaged over the distribution $X \mid T_{i}=1$ (Rubin, 1977).

Intuitively, this assumes that, conditioning on observable covariates, we can take assignment to treatment to have been random and that, in particular, un observables play no role in the treatment assignment; comparing two individuals with the same observable characteristics, one of whom was treated and one of whom was not. Under this assumption, the conditional treatment effect, $\left.\tau\right|_{T=1}$ is estimated by first estimating $\left.\tau\right|_{T=1, X}$, and then averaging over the distribution of $X$ conditional on $T=1$.

One way to estimate this equation would be by matching units on their vector of covariates, $\mathrm{X}_{\mathrm{i}}$. Rosenbaum and Rubin (1983) suggest the use of the propensity score-the probability of receiving treatment conditional on covariates - to reduce the dimensionality of the matching problem. Accordingly the probability of receiving treatment conditional on covariates is expressed as: let $p\left(X_{i}\right)$ be the probability of a unit $i$ having been assigned to a treatment defined as:

$$
\begin{aligned}
& p\left(X_{i}\right) \equiv \operatorname{Pr}\left(T_{i}=1 \mid X_{i}\right)=E\left(T_{i} \mid X_{i}\right), \text { then } \\
& \left(Y_{i 1}, Y_{i 0}\right) \perp T_{i}\left|X_{i} f\left(Y_{i 1}, Y_{i 0}\right) \perp T_{i}\right| p\left(X_{i}\right)
\end{aligned}
$$

Matching on the propensity score is essentially a weighting scheme as suggested by Heckman, Ichimura, and Todd (1998), which determines what weights are placed on comparison units when computing the estimated treatment effect:

$$
\left.\widehat{\tau}\right|_{T=1}=\frac{1}{|N|} \sum_{i \in N}\left(Y_{i}-\frac{1}{\left|J_{i}\right|} \sum_{j \in J_{i}} Y_{i}\right)
$$

where $\mathrm{N}$ is the treatment group, $|\mathrm{N}|$ the number of units in the treatment group, $\mathrm{J}_{\mathrm{i}}$ is the set of comparison units matched to treatment unit $i$ and $\left|J_{i}\right|$ is the number of comparison units in $J_{i}$.

\section{Matching Algorithms}

In choosing between different matching algorithms, Rosenbaum and Rubin (1983) suggested factors such as matching with or without replacement; how to set the standard for proximity; whether and how to weight cases in the analysis and number of comparison units to be matched to each treatment unit to be considered. In this regard, early matching estimators paired units in the treated group with those in the comparison group on a one-to-one basis which is matching without replacement. Matching without replacement may perform poorly when there is little overlap of the propensity scores or when the control group is small, since treated units are matched to observations that are not necessarily similar. As a result, many impact evaluation studies use sampling with replacement, allowing for one comparison case to serve as the match for more than one treated case (Dehejia and Wahba, 2002). However, as this study uses large number of sample, it uses matching without replacement approach. 
The most commonly used matching algorithms includes; nearest neighbor matching (NNM), radium matching, kernel and local-linear matching. NNM is one of the most straightforward matching procedures in which individual from the comparison group is chosen as a match for a treated individual in terms of the closest propensity score. Variants of nearest neighbor matching include "with replacement" and "without replacement," where, in the former case, an untreated individual can be used more than once as a match and, in the latter case, is considered only once.

To avoid the risk of poor matches, radius matching specifies a "caliper" or maximum propensity score distance by which a match can be made. The basic idea of radius matching is that it uses not only the nearest neighbor within each caliper, but all of the comparison group members within the caliper. In other words, it uses as many comparison cases as are available within the caliper, but not those that are poor matches. In many-to-one (radius) caliper matching with replacement, the estimator of program impact may be written as: $E(\Delta Y)=\frac{1}{N} \sum_{i=1}^{N}\left[Y_{1 i}-\bar{Y}_{0 j(i)}\right]$

where, $\bar{Y}_{0 j(i)}$ is the average outcome for all comparison individuals who are matched with case $i$ and $Y_{1 i}$ is the outcome for case $i$, and $N$ is the number of treated cases.

Kernel and local-linear matching are nonparametric matching estimators that compare the outcome of each treated person to a weighted average of the outcomes of all the untreated persons, with the highest weight being placed on those with scores closest to the treated individual. One major advantage of these approaches is the lower variance, which is achieved because more information is used. A drawback of these methods is that some of the observations used may be poor matches. Hence, the proper imposition of the common-support condition is of major importance for these approaches. When applying kernel matching, we have chosen the kernel function and the bandwidth parameter (ibid).

Matching on the propensity score is essentially a weighting scheme, which determines what weights are placed on comparison units when computing the estimated treatment effect. A good matching estimator does not eliminate too many of the original observations from the final analysis while it should at the same time yield statistically equal covariate means for treatment and control groups (Caliendo \& Kopeinig, 2008). Hence, a kernel matching algorithm is used to pair each mobile owner to similar non-mobile own erusing propensity score values in order to estimate the Average Treatment Effect on the Treated (ATT). We also analyzed the data using alternative matching estimators to check the robustness of our results.

\section{DATA}

The data used for this study is obtained from farm-household survey conducted during 2015/16 by Ethiopian Institute of Agricultural Research (EIAR)in collaboration with the International Maize and Wheat Improvement Center (CIMMYT). The data was collected with a purpose of wheat technology adoption analysis and its impacts on smallholder producers. The sampling frame covered seven major wheat-growing agro-ecological zones that account for over $85 \%$ of the national wheat area and production distributed in four major administrative regions of Ethiopia. A total of 2017 farm households in seven agro-ecological zones, in 26 zones (provinces), 61 districts and 122 kebeles /villages (local councils) were interviewed.

A multi-stage stratified sampling procedure was employed to select villages from each agro-ecology, and households from each kebele /village. First, agro-ecological zones that account for at least 3\% of the national wheat area each were selected from all the major wheat growing Regional States of Ethiopia: Amhara, Oromia, Tigray, and Southern Nations Nationalities and Peoples (SNNP). Second, based on proportionate random sampling, up to 21 villages in each agro-ecology, and 15-18 farm households in each village were randomly selected. The data was collected using a pre-tested structured questionnaire by trained and experienced enumerators who have good knowledge of the farming systems and speak the local language.

\section{RESULTS AND DISCUSSION}

\subsection{Descriptive Statistics for Observable Socioeconomic Chracteristics}

Several institutional, household and farm related variables affect mobile ownership as presented on table 1 below. The difference in means for these different variables before the matching, that is, using 
the full sample is indicated on the same table 1.The proportion of households that own mobile telephone is considerably high. Oromia region has the highest proportion of households that own mobile telephone which constitute $60 \%$ of sample households, followed by Tigray, SNNP and Amhara with 55\%, 51\% and 29\% of mobile ownership status, respectively. Key variables that explain household characteristics such as age, sex and education level of the households head significantly affect the household's mobile ownership status at $1 \%$ level. Higher proportion of male headed households have mobile telephone than households headed by female. Significant differences in terms of mobile telephone ownership were observed between male headed and female headed households. The average age of sample farmers that owned mobile is 43 years while farmers that don't have mobile is 48 years. Farm house holds heads that can read and write tend to have higher probability of owning mobile than those who can't read and write. The average family size of households that have mobile phone and that do not is 7.02 and 6.14, respectively implying the presence of significant difference between the two category of households at $1 \%$ level.

Being a model farmer, one of the most important approach to Ethiopia extension service which use model farmers to disseminate agricultural information to other farmers, is significantly important factor for mobile ownership. Model farmers are believed to have a wider network and connection with multitude of other farmers and agricultural experts, researchers and traders which mobile might have helped them maintain strong network and contact with different sources of agricultural information.

As livestock and land holding size are an important indicators of household wealth, it is expected that mobile ownership could be directly influenced by size of these two important holdings. The total number of livestock unit owned (TLU) by sample households were calculated using standard and most widely used conversion factors suggested by Storck et al(1991) to generate total livestock unit (TLU). Accordingly, the average TLU for farm households that own mobile telephone is 6.64 while the average TLU for non-mobile owners is 4.27 indicating significant difference at $1 \%$ level. Similarly, significant differences were observed between the two categories of households in terms of landholding size. The average landing size for mobile owners is 1.74 ha while for households that don't own mobile is about 1.35 ha.

As mobile telephone is instrumental for searching agricultural and market information and therefore, distance from an input market may affect mobile ownership status. Farmers that are located in the nearest distance to input market (seed and fertilizer) tend to own mobile than those who do not. The average distance for mobile owner is $3.87 \mathrm{~km}$ while for non-mobile owner it is about $4.63 \mathrm{~km}$ and such difference between the two groups is significant at $5 \%$ level.

Number of relatives outside the village that the household depend on for getting different information and number of traders that the household head have frequent contact may affect mobile ownership and the chi-square test indicated the existence of significant difference between mobile owners and nonowners in terms of these variables. Membership to cooperative and credit has no influence in mobile ownership status.

Table1. Summary of descriptive statistics of variables that affect mobile ownership and outcome variable (technical efficiency)

\begin{tabular}{|l|l|l|l|l|c|}
\hline \multirow{2}{*}{ Variables } & \multirow{2}{*}{ Unit } & \multicolumn{4}{|l|}{ Mobile ownership } \\
\cline { 3 - 6 } & & $\begin{array}{l}\text { Owners } \\
\text { Mean(SD) }\end{array}$ & $\begin{array}{l}\text { Non- owners } \\
\text { Mean(SD) }\end{array}$ & $\begin{array}{l}\text { Aggregate } \\
\text { Mean(SD) }\end{array}$ & $\chi^{2} /$ t-stat. \\
\hline Outcome variable & & & & & \\
\hline Technical efficiency & $\%$ & $0.76(0.12)$ & $0.65(0.15)$ & $0.70(0.15)$ & $(-14.1)^{* * *}$ \\
\hline \multicolumn{7}{|l|}{ Variables that affect mobile ownership } \\
\hline HHAGE & Years & $43.27(11.2)$ & $48.45(13.4)$ & $45.93(12.6)$ & $(8.34)^{* * *}$ \\
\hline HHSEX (Male=1) & Yes & $0.92(0.26)$ & $0.90(0.29)$ & $0.919(0.28)$ & $(-1.28)^{* * *}$ \\
\hline HHEDU (Read \& write=1) & Yes & $0.80(0.39)$ & $0.45(0.49)$ & $0.62(0.48)$ & $(15.37)^{* * *}$ \\
\hline FAMILYSIZE & $\#$ & $7.02(2.41)$ & $6.14(1.92)$ & $6.57(2.21)$ & $(-8.11)^{* * *}$ \\
\hline MODELFARMER & 1=Yes & $0.34(0.50)$ & $0.50(0.47)$ & $0.42(0.49)$ & $(-6.81)^{* * *}$ \\
\hline TLU & TLU & $6.64(4.82)$ & $4.27(3.60)$ & $5.43(4.40)$ & $(-11.23)^{* * *}$ \\
\hline LANDHOLDING & Ha & $1.74(1.46)$ & $1.35(1.08)$ & $1.54(1.29)$ & $(-1.64)^{* * *}$ \\
\hline INPUTMKT & Km & $3.87(3.62)$ & $4.63(3.99)$ & $4.26(3.84)$ & $(3.97)^{* *}$ \\
\hline NORLTOUTVLG & $\#$ & $8.28(26.2)$ & $5.23(8.7)$ & $6.72(19.4)$ & $(-3.15)^{* *}$ \\
\hline TRADERSOUTVLG & $\#$ & $3.96(4.66)$ & $3.26(4.75)$ & $3.60(4.72)$ & $(-2.99)^{* *}$ \\
\hline
\end{tabular}




\begin{tabular}{|l|l|l|l|l|l|}
\hline \hline COOPMEMBER & $1=y e s$ & $0.98(0.11)$ & $0.99(0.99)$ & $0.98(0.10)$ & $(0.83)$ \\
\hline CREDIT & $1=y e s$ & $0.07(0.26)$ & $0.06(0.24)$ & $0.06(0.25)$ & $(0.96)$ \\
\hline
\end{tabular}

\section{Source: Own computation, 2014/15}

The unconditional summary statistics discussed above based on table 1suggestthat mobile telephone may have a role in improving technical efficiency. However, given that mobile telephone ownership is endogenous, a simple comparison of the technical efficiency has no causal interpretation. That is, the differences may not be the result of mobile telephone, but instead might be due to other factors, such as differences in observed characteristics. Therefore, we need to employ a robust impact evaluation techniques such as PSM to control for observed and unobserved characteristics and determine the real impact of mobile telephone on technical efficiency of wheat producing farmers in Ethiopia.

\subsection{Estimation Results of Propensity Scores}

We used the logit model to estimate propensity scores. More than a dozen of selected variables presented in table 1 were included in the model. Because the matching procedure conditions on the propensity score but does not condition on individual covariates, one must check that the distribution of variables are 'balanced' across the mobile owner and non-owner groups. Rosenbaum and Rubin (1985) recommend that standardized bias and t-test for differences be used to check matching quality. If the covariates $X$ are randomly distributed across mobile owners and non-owner groups, the value of the associated pseudo $R^{2}$ should be fairly low and likelihood ratio should also be insignificant. A bootstrapping method was used to compute the standard error for the estimate of the mobile telephone impact.

All the variables included in the log it model show the expected sign. Age and education are found as significant variables for owning a mobile phone. As expected, young and educated household heads have higher probability of owing mobile phone than old and uneducated household heads. This finding is in agreement with the findings of Getaw and Godfrey (2015).

Proxy indicators for wealth of the households such as TLU and land-holding size are also significant factors that affect probability for owning mobile telephone. Better-off farmers who have higher number of livestock and larger land agricultural land are more likely to afford a mobile phone than those household who have less.

Being model farmers significantly influenced mobile ownership at 5\% level. This might be due to the fact that model farmers are relatively richer as a result of which they tend to own mobile. It might also due to the fact that for the purpose of maintaining wider social network model farmers have, they tend to own mobile for the purpose of maintaining their social network and interactions with traders, relatives, agricultural experts and individuals who lives outside their villages.

More interestingly, distance to input market is found to be an important determinant. Famers who are far from the input market have less probability of owning mobile phones than farmers who are close to these centers. This might be due to the lack of electric infrastructure necessary for charging mobile batteries.

Table2. Results of the log it regression model

\begin{tabular}{|l|l|l|}
\hline Variables & Coefficient & t-value \\
\hline HHAGE & $-0.0206^{* * * *}$ & $(-6.84)$ \\
\hline HHSEX & -0.199 & $(-1.59)$ \\
\hline HHEDU & $0.749^{* * * *}$ & $(9.81)$ \\
\hline FAMILY_SIZE & $0.0635^{* * *}$ & $(3.69)$ \\
\hline MODELFARMER & $0.207^{* *}$ & $(2.87)$ \\
\hline TLU & $0.0539^{* * *}$ & $(5.58)$ \\
\hline LANDHOLDING & $0.0827^{* *}$ & $(2.43)$ \\
\hline INPUTMKT & $-0.0653^{* * *}$ & $(-4.11)$ \\
\hline NORLTOUTVLG & $0.00573^{*}$ & $(2.05)$ \\
\hline TRADERSOUTVLG & 0.00637 & $(0.89)$ \\
\hline COOPMEMBER & -0.0335 & $(-0.10)$ \\
\hline CREDIT & $0.398^{*}$ & $(1.80)$ \\
\hline Constant & -0.333 & $(-0.85)$ \\
\hline$N$ & 1609 & \\
\hline$* * * * * *$ show significance at $10 \%, 5 \%$ and $1 \%$ levels, respectively &
\end{tabular}




\subsection{Estimation of Treatment Effect on the Treated}

As shown in Table 2, the propensity scores for each observation is calculated using logit model to predict the conditional probability of mobile telephone ownership. The propensity score for mobile owner range between 0.07064 and 0.9989 while for non-owners it range between 0.05293 and 0.94951, therefore, the region of common support for the distribution of estimated propensity scores of mobile owners and non-owners ranges between 0.07064 and 0.94951. Observations whose propensity score lies outside this range were discarded. The visual presentation of the distributions of the propensity scores which help us see the ful fillment of common support region are plotted in Figure 1. The density distributions of the estimated propensity scores for the two groups indicates that the common support condition is satisfied as there is substantial overlap in the distribution of the propensity scores of both mobile telephone owner and non-owner groups.

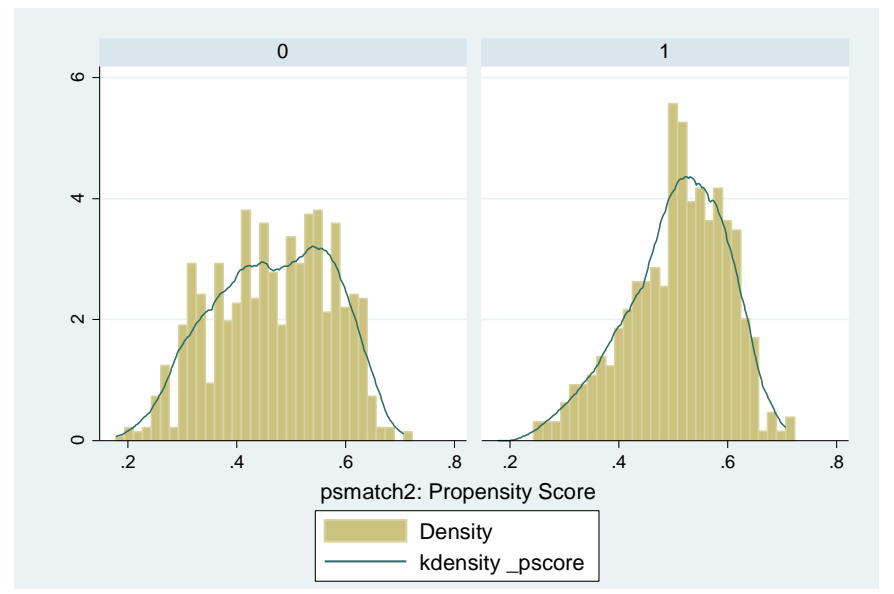

Figure1. Distributions of the Propensity Scores

The covariate balancing tests before and after matching is presented on table 3 . The bias substantially reduced, in the range of $22-42 \%$ through matching. The $p$-values of the likelihood ratio tests indicate that the joint significance of covariates was always rejected after matching. The pseudo $R^{2}$ also dropped significantly after matching. The lowpseudo $R^{2}$, low mean standardized bias, and the insignificant $p$-values of the likelihood ratio test after matching suggest that the proposed specification of the propensity score is fairly successful in terms of balancing the distribution of covariates between the two groups.

The different impact estimators were used to check for robustness of estimated treatment effect. The results show all the matching estimators revealed that mobile telephone ownership has a positive and statistically significant impact on technical efficiency. As indicated on table 4 the average impact of mobile ownership on technical efficiency is estimated by nearest neighbor matching (NNM), Kernel Matching (KM) and Radius (caliper) Matching (RM) methods. The table reports results based on the single NNM without replacement and the kernel estimator with 0.03 and0.06 bandwidth and bootstrapped standard errors with 100 replications. The finding reveal mobile telephone ownership significantly increase technical efficiency. Mobile telephone increase average technical efficiency in the range of $8-10 \%$ (Table 4).

Table3. Propensity score matching quality test

\begin{tabular}{|l|l|l|l|l|l|l|l|l|}
\hline \multirow{2}{*}{$\begin{array}{l}\text { Matching } \\
\text { algorithm }\end{array}$} & \multicolumn{2}{|l|}{ Before matching } & \multicolumn{2}{l|}{ After matching } & $\begin{array}{l}\text { Total } \\
\text { bias } \\
\text { Reduct } \\
\text { value })\end{array}$ \\
\cline { 2 - 9 } & Pseudd & $\begin{array}{l}\text { LR } \chi^{2} \\
\text { standardi } \\
\text { zed bias } \\
\text { ion } \\
(\%)\end{array}$ \\
\hline NNM1 & 0.163 & $327.53(\mathrm{p}=000)$ & 45.8 & 0.148 & $289.44(\mathrm{p}=0.101)$ & $\begin{array}{l}\text { Mean } \\
\text { standardize } \\
\mathrm{d} \text { bias }\end{array}$ \\
\hline KM2 & 0.163 & $327.53(\mathrm{p}=000)$ & 45.8 & 0.148 & $289.44(\mathrm{p}=0.11)$ & 35.4 & 22.7 \\
\hline KM3 & 0.163 & $327.53(\mathrm{p}=000)$ & 45.8 & 0.148 & $289.44(\mathrm{p}=0.13)$ & 35.4 & 22.7 \\
\hline $\begin{array}{l}\text { Radius/caliper } \\
\text { matching (0.01) }\end{array}$ & 0.163 & $327.53(\mathrm{p}=0.000)$ & 9.0 & 0.012 & $13.97(\mathrm{p}=0.11)$ & 5.2 & 42.0 \\
\hline $\begin{array}{l}\text { Radius/caliper } \\
\text { matching (0.06) }\end{array}$ & 0.163 & $327.53(\mathrm{p}=0.000)$ & 6.8 & 0.011 & $13.39(\mathrm{p}=0.14)$ & 4.8 & 29.4 \\
\hline
\end{tabular}


$\mathrm{NNM}^{1}=$ Nearest Neighbor matching without replacement

$\mathrm{KM}^{3}=$ with band width 0.06 and common support.

$\mathrm{KM}^{4}=$ with band width 0.03 and common support.

Table4. Average treatment effects: propensity score matching.

\begin{tabular}{|l|l|l|l|l|}
\hline \multirow{2}{*}{$\begin{array}{l}\text { Outcome } \\
\text { variable }\end{array}$} & Matching algorithm & \multicolumn{3}{|l|}{ Mean of outcome variables based on matched observations } \\
\cline { 3 - 5 } & & $\begin{array}{l}\text { Mobile telephone } \\
\text { owners }\end{array}$ & Non-mobile owners & ATT \\
\hline \multirow{2}{*}{$\begin{array}{l}\text { Technical } \\
\text { efficiency }\end{array}$} & $\mathrm{NNM}^{1}$ & 0.7535 & 0.6527 & $0.10(0.007) * * *$ \\
\cline { 2 - 5 } & $\mathrm{KM}^{2}$ & 0.7535 & 0.6527 & $0.10(0.007) * * *$ \\
\cline { 2 - 5 } & $\mathrm{KM}^{3}$ (caliper) & 0.7535 & 0.6527 & $0.10(0.007) * * *$ \\
\cline { 2 - 5 } & $\begin{array}{l}\text { Radius } \\
\text { matching (0.01) }\end{array}$ & 0.66 & $0.079(0.009)^{* * *}$ \\
\hline & $\begin{array}{l}\text { Radius (caliper) } \\
\text { matching (0.06) }\end{array}$ & 0.7416 & 0.6618 & $0.008)^{* * *}$ \\
\hline
\end{tabular}

Significance levels $(*, * *, * * *$ denote significance level at $10 \%, 5 \%$ and $1 \%$, respectively) are based on bootstrapped standard errors with 100 replications.

$\mathrm{NNM}^{1}=$ Nearest Neighbor matching without replacement

$\mathrm{KBM}^{3}=$ with band width 0.06 and common support.

$\mathrm{KBM}^{4}=$ with band width 0.03 and common support.

\section{CONCLUSIONS AND RECOMMENDATIONS}

Various efforts and substantial resources are being committed by Ethiopian governments to transform smallholder agriculture in Ethiopia. Apart from the many other support services, rapid expansion of mobile telephone services to farming communities has been one of the fundamental success achieved during the last couples of years. Significant proportion of farm households have already owned mobile telephone and using it for various social and economic purposes. Government of Ethiopia have invested quite large amount of financial resources to expand mobile telecom services in anticipation of its impact on smallholder farmers productivity and overall improvement in livelihood. The fact that there exists very scant information on whether the anticipated impact of mobile telephone expansion have been created or not is key issues policy makers need to understand in order to ensure the huge resources invested on mobile telecom expansion have added value to the agricultural economy of the country. This paper evaluated the impact of mobile telephone on technical efficiency of wheat producing farmers in Ethiopia to generate information on the impact of mobile telephone on technical efficiency of wheat producing farmers in Ethiopia. A propensity score matching method was employed to evaluate the impact and the result indicated that mobile telephone have created significant impact in improving technical efficiency. Farm households that own mobile telephone have up to $8-10 \%$ more technically efficient than those farm households that do not have. This implies that farmers that own mobile telephone are more productive than those who do not have. The study recommends, considering the immense potential of mobile telephone in improving technical efficiency and productivity, government of Ethiopia have to continue to expanding mobile telephone services accessible to the farm households that do not have access to it so that their efficiency and productivity would increased substantially.

\section{REFERENCES}

[1] Accenture and Vodafone (2011): The role of mobile in driving efficiency and sustainability in the food and agriculture value chain. Vodafone house, The Connection Newbury Berkshire, RG14 2FN, England.

[2] Alene, A. D., Manyong, V. M., manya, G., Mignouna, H. D., Bokanga,M., \& Odhiambo, G. (2008). Smallholder market participation under transactions costs: Maize supply and fertilizer demand in Kenya. Food Policy, 33(4), 318-328.

[3] Aker, J. C., \& Mbiti, I. M. (2010). Mobile phones and economic development in Africa. Journal of Economic Perspectives.

[4] Aker Jenny C. (2008) The Impact of Cell Phones on Grain Markets in Niger. Center for Global Development Economics Department, Fletcher School of Law and Diplomacy, Tufts University.

[5] Bassi, Laurie, "Estimating the Effects of Training Programs with Nonrandom Selection," this REVIEW 66:1 (February 1984), 36-43. 
[6] Caliendo, M., \& Kopeinig, S. (2008). Some practical guidance for the implementation of propensity score matching. Journal of Economic Surveys, 22, 31-72. http://dx.doi.org/10.1111/

[7] Carolyn Heinrich, Alessandro Maffioli and Gonzalo Vázquez (2010). A Primer for Applying Propensity Score Matching: Impact-Evaluation Guidelines. Inter-American Development Bank, 2010.

[8] Cochran, W. G., and D. B. Rubin, "Controlling Bias in Observational Studies: A Review," Sankhya, ser. A, 35:4 (December 1973), 417-446.

[9] Dehejia, R., and S. Wahba. 2002. "Propensity-score matching Methods for Non-experimental Causal Studies". The Review of Economic and Statistics 84(1): 151-161.

[10] Donald B. Rubin (1977) Assignment to Treatment Group on the Basis of a Covariate. Journal of Educational Statistics, Vol. 2, No. 1 (Spring, 1977), pp. 1-26

[11] Dominique Baron (2010). The Impact of Telecommunications Services on Doing Business in Ethiopia. Produced and distributed by Addis Ababa Chamber of Commerce and Sectoral Associations. Private Sector Development Hub/Addis Ababa Chamber of Commerce and Sectoral Associations, 2010. Addis Ababa, Ethiopia.

[12] Fafchamps, M., \& Minten, B. (2012). Impact of SMS-based agricultural information on Indian farmers. The World Bank Economic Review,26 (3), 383-414.

[13] Fafchamps, M. (2004). Market institutions in Sub-Saharan Africa: Theory and evidence. London: The MIT Press.

[14] Getaw T., and Godfrey B., (2015) Mobile Phones and Farmers' Marketing Decisions in Ethiopia. Journal of World Development Vol. 68, pp. 296-307.

[15] Heckman, J., H. Ichimura, and P. Todd. 1998. "Matching as an Econometric Evaluation Estimator". The Review of Economic Studies 65(2): 261-294.

[16] Jalan, J., and M. Ravallion. 2003. "Estimating the Benefit Incidence of an Antipoverty Program by Propensity-Score Matching”. Journal of Business \& Economic Statistics 21(1): 19-30.

[17] Lechner, M. 1999. "The Effects of Enterprise-Related Training in East Germany on Individual Employment and Earnings". Annalesd'Économieet de Statistique 55/56: 97-128.

[18] Lio, M., \& Liu, M. (2006). ICT and agricultural productivity: Evidence from cross-country data. Agricultural Economics, 34(3), 221-228.

[19] Minten, B., Stifel, D., \& Tamru, S. (2012). Structural transformation in Ethiopia: Evidence from cereal markets. IFPRI-ESSP II Working Paper 39: http://essp.ifpri.info/publications

[20] Muto, M., \& Yamano, T. (2009). The impact of mobile phone coverage expansion on market participation: Panel data evidence from Uganda.World Development, 37(12), 1887-1896.

[21] Persson, T., G. Tabellini, and F. Trebbi. 2003. "Electoral Rules and Corruption". Journal of the European Economic Association 1(4): 958-989.

[22] Roller, Lars-Hendrik and Leonard Waverman. 2001. "Telecommunications Infrastructure and Economic Development: A Simultaneous Approach." American Economic Review, 91(4):. DOI: 10.1257/aer.91.4.909

[23] Rosenbaum, Paul, Observational Studies (New York: Springer Verlag, 1995).

[24] Rosenbaum, P., and D. Rubin, (1983) "The Central Role of the Propensity Score in Observational Studies for Causal Effects," Bio metrika 70:1, 41-55.

[25] Rosenbaum, P., and D. Rubin, (1985) "Constructing A Control Group Using Multivariate Matched Sampling Methods That Incorporate The Propensity Score," The American Statistician Association, February 1985, Vol. 39, No. 1.

[26] Smith, J., and P. Todd. 2005. "Does matching overcome Lalonde's critique of non-experimental estimators?".Journal of Econometrics 125(1-2): 305-353.

[27] Stiglitz, J. E. (1986). The new development economics world development,14(2), 257-265.

[28] Tele Geography. 2011. http://www.telegeography.com/, accessed September 23, 2011.

[29] Williamson, O. (1979). Transaction-cost economics: The governance of contractual relations. Journal of Law and Economics, 22(2), 233-261.

[30] Williamson, O. (1985). The economic institutions of capitalism. New York: The Free Press.

[31] World Bank 2011. ICT in Agriculture: Connecting Smallholders to Knowledge, Networks, and Institutions, November 2011, Washington, DC 20433. 